\title{
A Determination of Potential $\alpha$-Glucosidase Inhibitors from Azuki Beans (Vigna angularis)
}

\author{
Yang Yao, Xuzhen Cheng, Lixia Wang, Suhua Wang and Guixing Ren * \\ Institute of Crop Science, Chinese Academy of Agricultural Sciences, South Xueyuan Road, \\ Haidian District No.80, Beijing 100081, China; E-Mails: yaoyang@caas.net.cn (Y.Y.); \\ chengxz@caas.net.cn (X.C.);wanglx@caas.net.cn (L.W.); wangsh@caas.net.cn (S.W.); \\ * Author to whom correspondence should be addressed; E-Mail: renguixing@caas.net.cn; \\ Tel.: +86-10-6211-5596; Fax: +86-10-6215-6596.
}

Received: 12 July 2011; in revised form: 1 September 2011 / Accepted: 21 September 2011 / Published: 28 September 2011

\begin{abstract}
A 70\% ethanol extract from azuki beans (Vigna angularis) was extracted further with $\mathrm{CH}_{2} \mathrm{Cl}_{2}$, EtOAc and n-BuOH to afford four fractions: $\mathrm{CH}_{2} \mathrm{Cl}_{2}$-soluble, EtOAc-soluble, $n$-BuOH-soluble and residual extract fractions. The EtOAc-soluble fractions showed the highest $\alpha$-glucosidase inhibitory activity. Two pure flavonoid compounds, vitexin and isovitexin, were isolated (using the enzyme assay-guide fractionation method) from the EtOAc-soluble fractions. We further evaluated the interaction between the flavonoid compounds and $\alpha$-glucosidase by fluorescence spectroscopy. Vitexin and isovitexin showed high inhibitory activities, with $\mathrm{IC}_{50}$ values of $0.4 \mathrm{mg} \cdot \mathrm{mL}^{-1}$ and $4.8 \mathrm{mg} \cdot \mathrm{mL}^{-1}$, respectively. This is the first study of the active compositions of azuki beans against $\alpha$-glucosidase.
\end{abstract}

Keywords: azuki beans; $\alpha$-glucosidase inhibitory; vitexin; isovitexin

\section{Introduction}

Interest in glucosidase inhibitors is growing because of its implications for the management of diabetes mellitus (DM). DM is a serious metabolic disorder that affects approximately $4 \%$ of the population worldwide and is expected to increase to affect $5.4 \%$ by 2025 [1]. Acting as a key enzyme for carbohydrate digestion, intestinal $\alpha$-glucosidase is one of the glucosidases located at the epithelium 
of the small intestine. $\alpha$-glucosidase has been recognized as a therapeutic target for the modulation of postprandial hyperglycemia, which is the earliest metabolic abnormality to occur in type 2 diabetes mellitus $[2,3]$. The inhibition on intestinal $\alpha$-glucosidases would delay the digestion and absorption of carbohydrates and consequently suppress the postprandial hyperglycemia [4].

Azuki beans have been a subject of extensive investigation due to their biological activities. In the past, they have been recommended as suitable foods for diabetic patients due to their high fiber and protein contents [5]. Recently, they have also been reported to contain considerable quantities of bioactive phytochemicals including phenolic compounds [6], which may offer extra benefits for the amelioration of diabetes. Itoh et al. [7] reported that azuki beans possess inhibition activity against $\alpha$ glucosidase in streptozotocin (STZ)-induced diabetic rats. However, the studies on anti-diabetic effects were focused on the activity of the extract; the active components of the extract were not ascertained. The present study was therefore carried out to isolate and identify the active compositions of azuki beans by enzyme assay-guided fractionation.

\section{Results and Discussion}

\subsection{Isolation of Active Compounds and Structural Determination}

Itoh et al. [7] investigated the antidiabetic effects of azuki beans on streptozotocin (STZ)-induced diabetic rats. We also observed that azuki beans showed the highest $\alpha$-glucosidase inhibition ability among sixteen legumes (data not shown). However, the active components of the extract were not ascertained. In this study, two pure compounds were separated from the EtOAc-soluble fraction by the method mentioned above; they were identified as vitexin and isovitexin (structures are shown in Figures 1 and 2), by comparison of their spectral data with those in the literature [8,9].

Figure 1. Chemical structures of vitexin.

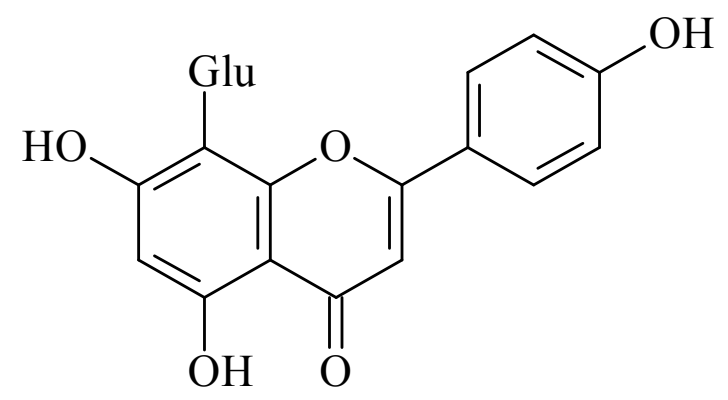

Vitexin (1): yellow powder. ${ }^{1} \mathrm{H}$ NMR (500 MHz, DMSO-d6) d: $13.15(1 \mathrm{H}, \mathrm{s}, \mathrm{OH}-5), 8.01(2 \mathrm{H}, \mathrm{d}$, $\left.J=8.7 \mathrm{~Hz}, \mathrm{H}-2^{\prime}, 6^{\prime}\right), 6.86$ (2H, d, $J=8.7 \mathrm{~Hz}, \mathrm{H}-3$ ', 5'), 6.76 (1H, s, H-3), 6.23 (1H, s, H-6), 4.69 (1H, $\mathrm{d}, J=9.8 \mathrm{~Hz}, \mathrm{H}-1^{\prime}$ of glu), 3.85-3.22 (6H, m, glucosyl H). ${ }^{13} \mathrm{C}$ NMR (DMSO-d 6) d: 182.0 (C-4), 164.8 (C-2), 162.7 (C-7) 161.3 (C-4'), 160.4 (C-5),156.09 (C-9), 128.5 (C-2', 6'), 121.2 (C-1'), 115.8 (C-3', 5'), 104.7 (C-10), 104.1 (C-8), 102.4 (C-3), 98.2 (C-6). Positive ESI-MS: m/z 433 [M + H] . 
Figure 2. Chemical structures of isovitexin.<smiles>O=c1cc(-c2ccc(O)cc2)oc2cc(O)c(Cl)c(O)c12</smiles>

Isovitexin (2): yellow powder. ${ }^{1} \mathrm{H}$ NMR (500 MHz, DMSO-d6) d: $13.55(1 \mathrm{H}, \mathrm{s}, \mathrm{OH}-5), 7.93(2 \mathrm{H}, \mathrm{d}$, $\left.J=8.8 \mathrm{~Hz}, \mathrm{H}-2^{\prime}, 6^{\prime}\right), 6.93(2 \mathrm{H}, \mathrm{d}, J=8.8 \mathrm{~Hz}, \mathrm{H}-3$ ', 5'), 6.78 (1H, s, H-3), 6.51 (1H, s, H-8), $4.58(1 \mathrm{H}$, $\mathrm{d}, J=9.8 \mathrm{~Hz}, \mathrm{H}-1$ of glu), 4.03-3.11 (6H, m, glucosyl H). ${ }^{13} \mathrm{C}$ NMR (DMSO d6) d: 181.9 (C-4), 163.5 (C-2), 163.3 (C-7), 161.6 (C-4'), 160.6 (C-5), 158.2 (C-9), 128.4 (C-2', 6'), 121.1 (C-1'), 116.06 (C-3', 5'), 108.9 (C-6), 103.4 (C-10), 102.8 (C-3), 93.64 (C-8). Positive ESI-MS: $m / z 433$ [M + H] .

\subsection{Alpha-Glucosidase Inhibition Activities}

To determine the $\alpha$-glycosidase inhibition ability in vitro, we calculated the $\mathrm{IC}_{50}$ values (Table 1 ). The EtOAc-soluble fraction had the highest $\alpha$-glucosidase inhibitory activity of the four partition parts. Vitexin was the most active $\left(\mathrm{IC}_{50}\right.$ of $\left.0.4 \mathrm{mg} \cdot \mathrm{mL}^{-1}\right)$, followed by isovitexin $\left(\mathrm{IC}_{50}\right.$ of $\left.4.8 \mathrm{mg} \cdot \mathrm{mL}^{-1}\right)$.

Table 1. Alpha-glucosidase inhibitory activity of $\mathrm{CH}_{2} \mathrm{Cl}_{2}$-soluble, EtOAc-soluble, $n$-BuOH-soluble, residual extract, vitexin and isovitexin.

\begin{tabular}{lc}
\hline Extracts/compounds & $\mathbf{I C}_{\mathbf{5 0}}$ \\
\hline $\mathrm{CH}_{2} \mathrm{Cl}_{2}$-soluble & $>500$ \\
EtOAc-soluble & 53.74 \\
n-BuOH-soluble, & 173.69 \\
Residual extract & $>500$ \\
Vitexin & 0.4 \\
Isovitexin & 4.8 \\
Acarbose & 0.45 \\
\hline \multicolumn{2}{c}{$\mathrm{IC}_{50}$ was expressed as $\mathrm{mg} \cdot \mathrm{mL}^{-1}}$.
\end{tabular}

\subsection{Fluorescence Spectra}

Fluorescence quenching can be divided into two types: dynamic quenching and static quenching. Dynamic quenching stems from the collision between two fluorescent luminophors, while static quenching arises from the formation of a new nonfluorescent complex that forms between the fluorescent luminophors and quencher [10]. Dynamic quenching follows the Stern-Volmer equation [11]:

$$
F_{0} / F=1+K_{\mathrm{sv}}[Q]=1+K_{\mathrm{q}} \tau_{0}[Q]
$$

where $F_{0}$ and $F$ are the fluorescence intensities of the fore-and-aft interaction between $\alpha$-glucosidase and flavonoid, $[Q]$ is the concentration of quencher and flavonoid, and $\tau_{0}$ is the average life of the 
fluorescent substance without the quencher, valued at approximately $10^{-8} \mathrm{~s} . K_{\mathrm{sv}}$ and $K_{\mathrm{q}}$ are the dynamic quenching constant and rate constant in the process of double molecule quenching [12].

The quenching fluorescence spectra of $\alpha$-glucosidase by flavonoids were recorded at 25 and $37{ }^{\circ} \mathrm{C}$ (Figures 3 and 4). The values of $K_{\mathrm{sv}}$ and $K_{\mathrm{q}}$ were obtained with the Stern-Volmer equation from plots of linear equations obtained by $F_{0} / F v s$. [Q]. The values of $K_{\mathrm{sv}}$ decreased with the increase of temperature, and $K_{\mathrm{q}}$ was greater than $2.0 \times 10^{10}$ (Table 2). Therefore, the process of quenching is a static quenching by the formation of a complex.

Table 2. Constants of $K_{\mathrm{sv}}$ and $K_{\mathrm{q}}$ of the interaction between $\alpha$-glucosidase and vitexin, isovitexin.

\begin{tabular}{ccccc}
\hline & $\begin{array}{c}\boldsymbol{T} \\
\left({ }^{\circ} \mathbf{C}\right)\end{array}$ & $\begin{array}{c}\boldsymbol{K}_{\mathbf{S V}} / \mathbf{1 0 5} \\
\left(\mathbf{L} \cdot \mathbf{m o l}^{-\mathbf{1}}\right)\end{array}$ & $\begin{array}{c}\boldsymbol{K}_{\mathbf{q}} / \mathbf{1 0 1 3} \\
\left(\mathbf{L} \cdot \mathbf{m o l}^{-1} \cdot \mathbf{S}^{-\mathbf{1}}\right)\end{array}$ & $\boldsymbol{R}^{\mathbf{2}}$ \\
\hline Vitexin & 25 & 1.38 & 1.38 & 0.9436 \\
& 37 & 1.13 & 1.13 & 0.9627 \\
Isovitexin & 25 & 1.06 & 1.06 & 0.9829 \\
& 37 & 0.98 & 0.98 & 0.9807 \\
\hline
\end{tabular}

Static quenching follows the equations [13]:

$$
\begin{gathered}
\lg \frac{F_{0}-F}{F}=\lg K_{\mathrm{A}}+\mathrm{n} \lg [Q]_{\mathrm{f}} \\
\text { [flavonoid]f }=[\text { flavonoid }]-n[\alpha \text {-glucosidase-flavonoid } \mathrm{n}] \\
{[\alpha \text {-glucosidase-flavonoidn }]=\frac{F_{0}-F}{F_{0}-F_{\infty}}[\alpha \text {-glucosidase }]}
\end{gathered}
$$

Here, $[\mathrm{Q}]_{\mathrm{f}}$ is the concentration of free flavonoid, [flavonoid $]_{\mathrm{f}}$; and $\left[\alpha \text {-glucosidase-flavonoid }{ }_{n}\right]_{\text {is }}$ the concentration of $\alpha$-glucosidase bound with the flavonoid.

The vitexin binding constant $\left(K_{\mathrm{A}}\right)$ is higher than the isovitexin constant (Table 3$)$. The number of binding sites $(n)$ was close to one at $37{ }^{\circ} \mathrm{C}$, which is the most suitable temperature for the flavonoid molecules to bind with $\alpha$-glucosidase.

Table 3. Values of $K_{\mathrm{A}}$ and $n$ of the interaction between $\alpha$-glucosidase and vitexin, isovitexin.

\begin{tabular}{ccccc}
\hline & $\boldsymbol{T}$ & $\boldsymbol{K}_{\mathbf{A}} / \mathbf{1 0 5}$ & $\boldsymbol{n}$ & $\boldsymbol{R}^{\mathbf{2}}$ \\
\hline Vitexin & $\left({ }^{\circ} \mathbf{C}\right)$ & $\left(\mathbf{L} \cdot \mathbf{m o l}^{-\mathbf{1}}\right)$ & & 0.9865 \\
& 25 & 1.23 & 1.21 & 0.9940 \\
Isovitexin & 37 & 1.37 & 1.24 & 0.9671 \\
& 25 & 1.19 & 1.09 & 0.9513 \\
\hline
\end{tabular}


Figure 3. The effect of vitexin on fluorescence spectrum of $\alpha$-glucosidase after they were added to the enzyme solution.

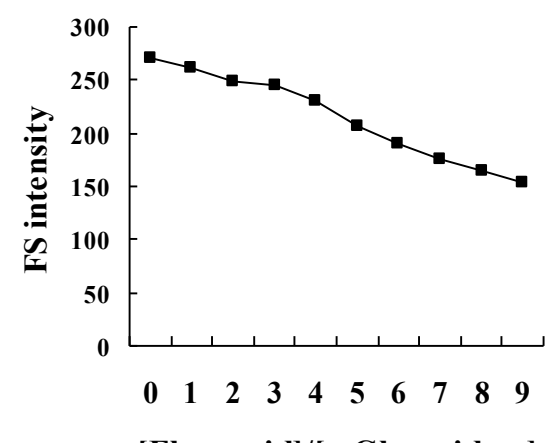

[Flavonoid]/[a-Glucosidase]

Figure 4. The effect of isovitexin on fluorescence spectrum of $\alpha$-glucosidase after they were added to the enzyme solution.

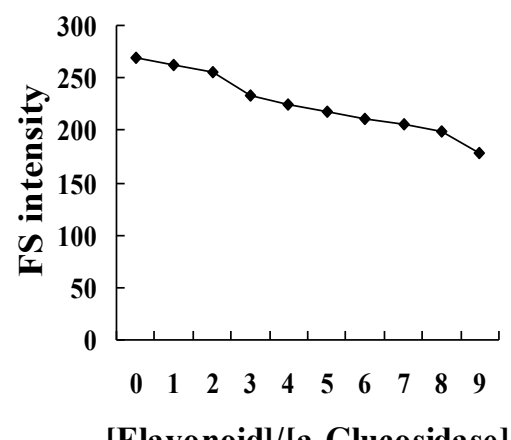

[Flavonoid]/[a-Glucosidase]

\section{Materials and Methods}

\subsection{Materials}

Azuki beans were provided by the Chinese National Genebank (Beijing, China). Rat intestinal acetone powder was purchased from Sigma-Aldrich (St. Louis, MO, USA). Acarbose was purchased from Bayer Health Care Pharmaceuticals, Inc. (USA). All chemicals used were of analytical grade and were obtained from Beijing Chemical Reagent (Beijing, China). Silica gel (200-300 mesh) for column chromatography was purchased from Qingdao Marine Chemical Company (Qingdao, China). Sephadex LH-20 was purchased from GE Healthcare (Sweden, USA).

\subsection{Isolation and Identification of Active Compounds}

Dried Azuki beans $(3.0 \mathrm{~kg})$ were crushed and twice extracted with $70 \%$ ethanol $(3 \times 10 \mathrm{~L})$ for $2 \mathrm{~h}$ at $60{ }^{\circ} \mathrm{C}$. The extracts were combined and concentrated under vacuum at $50{ }^{\circ} \mathrm{C}$. Then, the concentrated extracts were partitioned with $\mathrm{CH}_{2} \mathrm{Cl}_{2}$, EtOAc and n-BuOH to offer four extracts: the $\mathrm{CH}_{2} \mathrm{Cl}_{2}$-soluble, EtOAc-soluble, $\mathrm{n}-\mathrm{BuOH}$-soluble and residual extract fractions. Each extract was evaporated to dryness under reduced pressure, while the residual extract fraction was frozen to dryness. Therefore, five extracts were obtained in total. A small amount of each fraction was redissolved in $50 \%$ dimethyl sulfoxide (DMSO), and these mixture solutions were subjected to $\alpha$-glucosidase inhibitory activity assays. 
The EtOAc-soluble fraction ( $25 \mathrm{~g}$ ) was subjected to a silica gel chromatography column, using an EtOAc/ $/ \mathrm{MeOH} / \mathrm{H}_{2} \mathrm{O}$ system as the eluent, and the polarity of the eluent was increased by increasing the ratio of EtOAc during the process. The separation was monitored by TLC, and four fractions were obtained. Fraction 3 [EtOAc: $\mathrm{MeOH}: \mathrm{H}_{2} \mathrm{O}=8: 1: 0.2$ (v:v:v)] showed strong inhibitory activities against $\alpha$-glucosidase. A further separation was completed using a combination of Sephadex LH-20 column chromatography, with $\mathrm{MeOH}$ as the eluent, and reversed-phase TLC to monitor the isolation.

\subsection{Evaluation of $\alpha$-Glucosidase Inhibitory Activity}

The $\alpha$-glucosidase inhibitory activity was determined as previously described with slight modifications [14,15]. The inhibition activity of $\alpha$-glucosidase $\left(1\right.$ unit $\left.\cdot \mathrm{mL}^{-1}\right)$ was assayed using $50 \mu \mathrm{L}$ of extracts with varying concentrations incubated with $100 \mu \mathrm{L}$ of $0.1 \mathrm{M}$ phosphate buffer (pH 7.0) in 96-well plates at $37^{\circ} \mathrm{C}$ for $10 \mathrm{~min}$. After preincubation, $50 \mu \mathrm{L}$ of $5 \mathrm{mM} p$-nitrophenyl- $\alpha$-Dglucopyranoside solution in $0.1 \mathrm{M}$ phosphate buffer $(\mathrm{pH} 7.0)$ was added to each well at varying time intervals. The reaction mixtures were incubated at $37^{\circ} \mathrm{C}$ for $5 \mathrm{~min}$. The absorbance readings were recorded at $490 \mathrm{~nm}$ on a microplate reader before and after incubation (BioRad, IMAX, Hercules, USA). The results were expressed as a percent of $\alpha$-glucosidase inhibition and calculated according to the following equation:

$$
\% \text { inhibition }=\mathrm{Abs}^{\mathrm{control}}-\mathrm{Abs}^{\text {extract }} \times 100 / \mathrm{Abs}^{\text {control }}
$$

The $\mathrm{IC}_{50}$ value was defined as the concentration of bean extracts (acarbose) required to inhibit $50 \%$ of the enzyme activity.

\subsection{Measurement of Fluorescence Spectra}

The fluorescence spectra were determined using the method reported by Li et al. [12]. The $\alpha$-glucosidase was prepared by dissolving solid $\alpha$-glucosidase into phosphate buffer $\left(0.1 \mathrm{~mol} \cdot \mathrm{L}^{-1}, \mathrm{pH} 6.8\right.$, with $0.1 \mathrm{~mol} \cdot \mathrm{L}^{-1} \mathrm{NaCl}$ ), and vitexin (or isovitexin) was dissolved in $60 \%$ ethanol. For the FS measurement, a solution of $1.0 \mathrm{~mL}$ of $\alpha$-glucosidase was added to a fluorescence cuvette at a given temperature and titrated with flavonoid for $5 \mathrm{~min}$. Fluorescence spectra of the $\alpha$ glucosidase and $\alpha$-glucosidase-flavonoid mixture were recorded in the range from 315 to $500 \mathrm{~nm}$. The slits for both excitation and emission were set at $10 \mathrm{~nm}$ with an excitation wavelength of $295 \mathrm{~nm}$ and an optical path of $10 \mathrm{~mm}$ (Hitachi F-2500 fluorescence spectrophotometer, Japan).

\section{Conclusion}

In conclusion, two major active components, vitexin and isovitexin, were isolated from the azuki bean. There is a static quenching interaction between flavonoid compounds and $\alpha$-glucosidase, and the most suitable temperature is $37^{\circ} \mathrm{C}$.

\section{Acknowledgements}

The present study was supported by the earmarked fund for Modern Agro-industry Technology Research System nycytx-018 (to Guixing Ren). 


\section{References}

1. Yao, Y.; Ren, G.; Wang, J.S.; Chen, F.; Wang, M.F. Antidiatbetic of mung bean extracts in diabetic KK- A ${ }^{\mathrm{y}}$ mice. J. Agric. Food Chem. 2008, 56, 8869-8873.

2. Krentz, A.J.; Bailey, C.J. Oral antidiabetic agents current role in type 2 diabetes mellitus. Drugs 2005, 65, 385-411.

3. Lebovitz, H.E. Postprandial hyperglycemic state: Importance and consequences. Diabetes Res. Clin. Pract. 1998, 40, 27-28.

4. Puls, W.; Keup, U.; Krause, H.P.; Thomas, G.; Hofmeister, F. Glucosidase inhibition: A new approach to the treatment of diabetes, obesity, and hyperlipoproteinaemia. Naturwissenschaften 1977, 64, 536-537.

5. Lee, S.H.; Chun, H.K.; Park, H.J.; Lee, Y.S. Supplementary effect of the high dietary fiber rice on blood glucose in diabetic KK-A $\mathrm{A}^{\mathrm{y}}$ mice. Korean J. Nutr. 2004, 37, 75-80.

6. Lin, P.Y.; Lai, H.M. Bioactive compounds in legumes and their germinated products. J. Agric. Food Chem. 2006, 54, 3807-3814.

7. Itoh, T.; Kita, N.; Kurokawa, Y.; Kobayashi, M.; Horio, F.; Furuichi, Y. Suppressive effect of a hot water extract of adzuki beans (Vigna angularis) on hyperglycemia after sucrose loading in mice and diabetic rats. Biosci. Biotechnol. Biochem. 2004, 68, 2421-2416.

8. Hosoya, T.; Yun, Y.S.; Kunugi, A. Five novel flavonoids from Wasabia japonica. Tetrahedron. 2005, 61, 7037-7044.

9. Tanaka, J.C.A.; Conceicao da Silva, C.; Dias Filho, B.P.; Nakamura, V.; Ernesto de Carvalho, J.; Foglio, M.A. Chemical constituents of Luehea divaricata Mart. (Tiliaceae). Quimica Nova. 2005, $28,834-837$.

10. Yang, P.; Gao, F. Principles of Bioinorganic Chemistry; Science Press: Beijing, China, 2002; pp. 331-332.

11. Zhang, X.W.; Zhao, F.L.; Li, K.A. Progress in the research of the interaction between drug and serum protein in vitro. Chemistry 1999, 20, 1063-1067.

12. Li, Y.Q.; Zhou, F.C.; Gao, F.; Bian, J.S.; Shan, F. Comparative evaluation of quercetin, isoquercetin and rutin as inhibitors of $\alpha$-glucosidase. J. Agric. Food Chem. 2009, 57, $11463-11468$.

13. Xie, M.Y.; Jiang, M.; Li, S.; Liu, Y. Study on the interaction of $\beta-1,2,3,4,6$-Penta-O-galloylD-glucopyranose with human serum albumin. Acta Chem. Sin. 2004, 62, 1460-1466.

14. Nishioka, T.; Wabata, J.; Aoyama, Y. Baicalein, $\alpha$-glucosidase inhibitor from Scutellaria baicalensis. J. Nat. Prod. 1998, 61, 1413-1415.

15. Yao, Y.; Wei, S.; Meijing, Z.; Ren, G. Antioxidant and $\alpha$-glucosidase inhibitory activity of colored grains in China. J. Agric. Food Chem. 2010, 58, 770-774.

(C) 2011 by the authors; licensee MDPI, Basel, Switzerland. This article is an open access article distributed under the terms and conditions of the Creative Commons Attribution license (http://creativecommons.org/licenses/by/3.0/). 